\title{
LAPAROSCOPIC GYNAECOLOGICAL PROCEDURES UNDER SPINAL ANAESTHESIA USING DEXMEDETOMIDINE INFUSION FOR SEDATION: A FEASIBILITY STUDY
}

\author{
Arindam Phukan', Deba Gopal Pathak2, Laishram Chandralekha Singha3 ${ }^{3}$ Anindya Baruah', Rupankar Nath ${ }^{5}$
}

${ }_{1}^{1}$ Postgraduate, Department of Anaesthesiology, Silchar Medical College.

2 Professor and HOD, Department of Anaesthesiology, Silchar Medical College.

3 Postgraduate, Department of Anaesthesiology, Silchar Medical College.

${ }^{4}$ Registrar, Department of Anaesthesiology, Gauhati Medical College.

5Anaesthetist, Department of Anaesthesiology, Silchar Medical College.

\begin{tabular}{l} 
ABSTRACT \\
\hline BACKGROUND AND AIM \\
Laparoscopic procedures are conventionally done under general anaesthesia for avoiding patient discomforts and other \\
problems related to pneumoperitoneum that occur during laparoscopy under spinal anaesthesia. Here a study was designed to \\
look for the possibility of using intravenous dexmedetomidine infusion to overcome these problems in patients undergoing \\
laparoscopic gynaecological procedures of short duration, i.e. 1 hour or less under spinal anaesthesia.
\end{tabular}

\section{METHODS}

Sixty patients planned for laparoscopic gynaecological procedures of short duration were given spinal anaesthesia along with intravenous dexmedetomidine infusion. During the surgery, patient's pain or discomfort was managed by supplemental pentazocine injection (15 $\mathrm{mg}$ ) and all effects and adverse effects were recorded.

\section{RESULTS}

None of the cases required conversion to general anaesthesia or conversion to open surgery. Nineteen patients (31.6\%) required supplemental injection of pentazocine $(15 \mathrm{mg})$ and 5 patients $(8.33 \%)$ required pentazocine (30 $\mathrm{mg})$. Bradycardia occurred in sixteen $(26.7 \%)$ patients. Hypotension also occurred in sixteen $(26.7 \%)$ patients.

\section{CONCLUSIONS}

Spinal anaesthesia along with dexmedetomidine infusion maybe feasible for short laparoscopic gynaecological procedures with careful monitoring for the development of possible adverse effects. However, additional analgesia sedation maybe required for a satisfactory outcome.

\section{KEYWORDS}

Laparoscopic, Dexmedetomidine, Pentazocine, Spinal Anaesthesia, Sedation.

HOW TO CITE THIS ARTICLE: Phukan A, Pathak DG, Singha LC, et al. Laparoscopic gynaecological procedures under spinal anaesthesia using dexmedetomidine infusion for sedation: a feasibility study. J. Evolution Med. Dent. Sci. 2016;5(64):4578-4581, DOI: $10.14260 /$ jemds/2016/1043

\section{INTRODUCTION}

General Anaesthesia (GA) is considered the anaesthetic technique of choice for laparoscopic procedures including laparoscopic gynaecological procedures. Regional anaesthesia as a sole technique was initially advocated for cases who were considered high-risk candidates for general anaesthesia.[1,2] However, nowadays, it is also opted as a routine technique for healthy patients.[3,4] Studies have demonstrated that surgeries like laparoscopic cholecystectomy can be safely performed under spinal anaesthesia.[5] However, anxiety and other problems related to pneumoperitoneum like shoulder tip pain causes discomfort to the patients during these procedures under spinal anaesthesia. These problems can be overcome by providing proper sedation during the procedure.

Financial or Other, Competing Interest: None.

Submission 04-07-2016, Peer Review 28-07-2016,

Acceptance 03-08-2016, Published 11-08-2016.

Corresponding Author:

Dr. Laishram Chandralekha Singha,

Postgraduate,

Department of Anaesthesiology,

Silchar Medical College, Ghungoor,

Silchar-788014, Cachar, Assam.

E-mail: chandralekha.singha@gmail.com

DOI: $10.14260 /$ jemds/2016/1043
Dexmedetomidine is a selective $\alpha 2$-adrenoreceptor agonist, which has sedative, analgesic, anxiolytic properties with preservation of the ventilatory drive.[6] Also, intravenous dexmedetomidine administration with spinal anaesthesia has been said to prolong the effects of the sensory and motor block along with a sedative effect.[7]

Pentazocine is a mixed agonist-antagonist analgesic with agonistic action at $\kappa$ and $\sigma$ receptors and a weak antagonistic action at $\mu$ receptor. Pentazocine is a benzomorphan derivative. It alters perception of and response to pain and produces generalised CNS depression by binding to opiate receptors in the CNS and acting as a partial agonist/antagonist.

Although, there are a number of studies on laparoscopic cholecystectomy and appendicectomy under spinal anaesthesia. Very few studies have been reported on laparoscopic gynaecological procedures under spinal anaesthesia. In our study, we intended to analyse the feasibility of performing laparoscopic gynaecological procedures of short duration under spinal anaesthesia along with dexmedetomidine infusion for sedation and pentazocine injection as a rescue sedative and analgesic if required. 


\section{MATERIALS AND METHODS}

After obtaining Institutional Ethical Committee approval and written informed consent from the patients, a clinical study involving 60 patients undergoing laparoscopic gynaecological procedure under spinal anaesthesia was done during the period of November 2015 to April 2016 in Silchar Medical College and Hospital.

\section{Inclusion Criteria Were}

1) Patients aged between 20-55 yrs. 2) Patients with ASA grade I and II. 3) Patients scheduled for short laparoscopic gynaecological procedure.

\section{Exclusion Criteria Were}

1) Patient's refusal 2) Patients hypersensitive to local anaesthetics 3) Short stature, i.e., height below $152 \mathrm{~cm}$ (5 feet) 4) Overweight patients (Weight $>120 \mathrm{~kg}$ ) 5) Patients with history of hypertension, diabetes mellitus, psychiatric disorder, or any other systemic disease 6) Patients with coagulation disorders, patients on anticoagulants or aspirin 7) Patients with skin sepsis in lumbar region, patients with pre-existing neurological disorders or spine deformation 8) Cases belonging to ASA III and above.

Upon the patient's arrival in the operating room, standard routine monitoring including noninvasive automated blood pressure, pulse oximetry, and electrocardiography was started. Oxygen was administered at $6 \mathrm{~L} / \mathrm{min}$ via a facemask and EtCO2 was monitored throughout the procedure. Under all strict aseptic and antiseptic precaution with the patient in left lateral position, lumbar puncture was performed at L2-L3 intervertebral space with 25G Quincke needle and $1.6 \mathrm{~mL}$ of $5 \%$ lignocaine was given slowly after free flow of clear CSF was obtained. After completion of the procedure, patient was immediately turned to supine position. A $10^{\circ}$ head down tilt was maintained for 10 minutes allowing the drug to fix. In these 10 minutes, a loading dose of dexmedetomidine 1 $\mu \mathrm{gm} / \mathrm{kg}$ was infused. Level of sensory block was confirmed. During the surgery, continuous dexmedetomidine infusion at a rate of $0.5 \mu \mathrm{gm} / \mathrm{kg} / \mathrm{hr}$ was given and patient's discomfort if any like shoulder tip pain, abdominal discomfort, anxiety, etc. was managed by pentazocine injection ( $15 \mathrm{mg}$ ).

The sensory block level was assessed by the pinprick test using a 24-gauge hypodermic needle while the motor block level was assessed by the modified Bromage scale $0=$ no paralysis; $1=$ unable to raise extended leg; $2=$ unable to flex knee; $3=$ unable to flex ankle) and recorded $10 \mathrm{~min}$. after placement in the supine position. The level of sedation was evaluated immediately before dexmedetomidine loadingdose infusion (baseline) and at 5 mins., 15 mins., 25 mins. from the starting of the procedure and one at the end of the surgery using the Ramsay sedation score. Hypotension was defined as a $20 \%$ decrease from the baseline systolic blood pressure and was treated primarily with intravenous crystalloid fluid and $6 \mathrm{mg}$ mephentermine bolus intravenously. Bradycardia was defined as a heart rate of less than 60 beats per minute and was treated with $0.6 \mathrm{mg}$ of intravenous atropine. Adverse effects like referred shoulder pain, abdominal discomfort, hypotension, nausea were recorded. Postoperative pain scores were assessed at 1, 3, 6, 12 , and 24 hours postoperatively using a 0 to $10 \mathrm{~cm}$ visual analogue scale $(0=$ no pain, $10=$ worst pain imaginable).
The overall level of patient satisfaction was also assessed using a four point scale (Excellent, good, average, and poor) on the first postoperative day.

\section{RESULTS AND OBSERVATIONS}

The procedures included in the study includes diagnostic laparoscopies (25 out of 60), laparoscopic tubal occlusion (20 out of 60 ), and laparoscopic ovarian drilling (15 out of 60 ). The demographic data of the patients included in the study are summarised in Table 1. A sensory level of T3, T4, T5, and T6 was obtained in $5,38,12$, and 5 patients respectively as shown in Fig. 1. A modified Bromage scale score of 3, 2 was achieved in 38 and 22 patients respectively and is shown in Fig. 2. The mean operative duration was $35.4 \pm 3.2 \mathrm{~min}$. The mean duration of anaesthesia was $65.8 \pm 4.6$ mins. During the operation, the intra-abdominal $\mathrm{CO} 2$ gas pressure was maintained at 12 and $14 \mathrm{mmHg}$ in 39 and 21 patients, respectively. Adverse effects observed during surgery are summarised in Table 2.

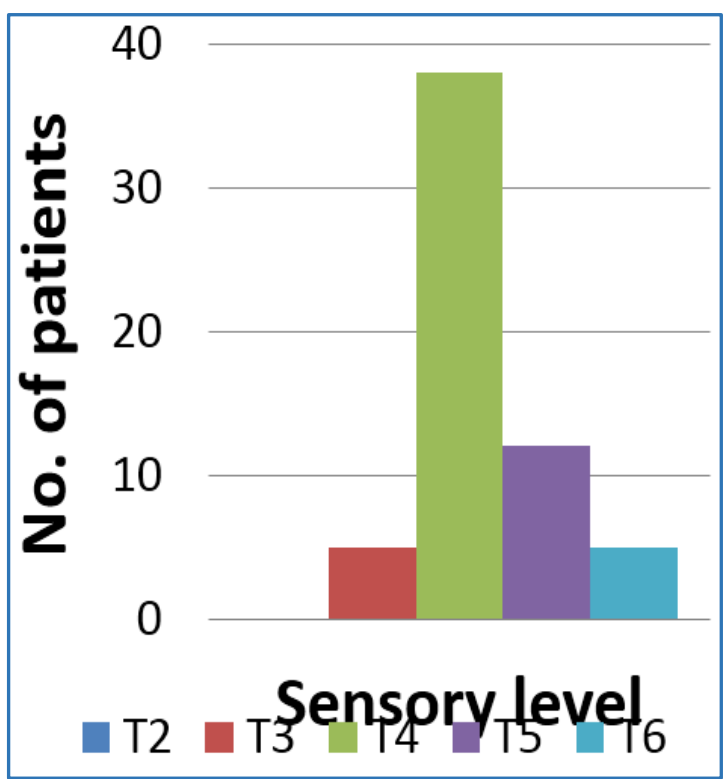

Fig. 1

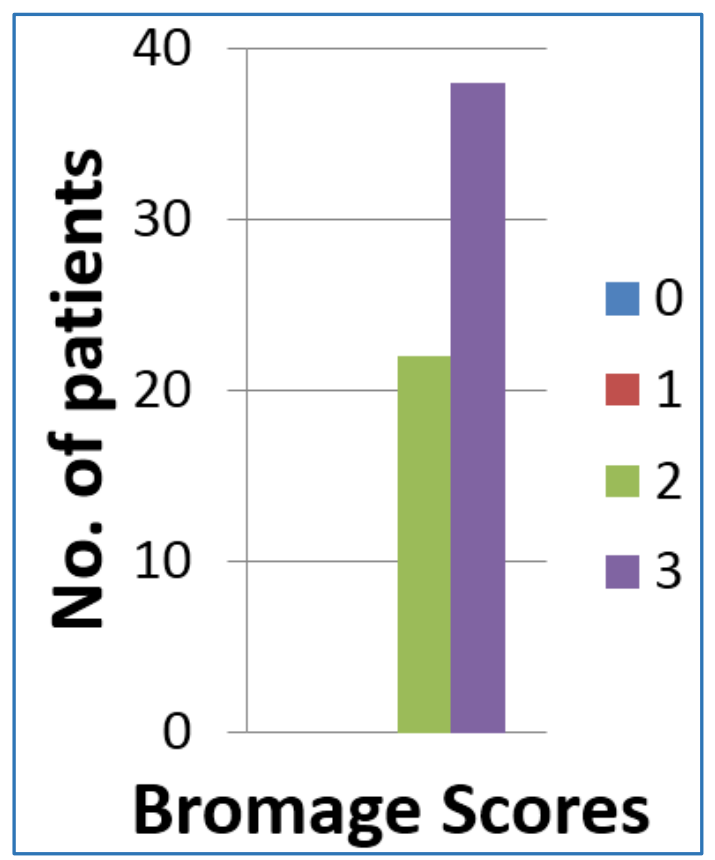

Fig. 2 


\begin{tabular}{|c|c|}
\hline Sex (M/F) & $0 / 60$ \\
\hline Age (yr.) & $32 \pm 14.0$ \\
\hline Height (cm) & $158 \pm 7.7$ \\
\hline Weight (kg) & $55 \pm 10.3$ \\
\hline ASA Status (I/II) & $48 / 12$ \\
\hline \multicolumn{2}{|c|}{ Table 1: Demographic Data } \\
\hline
\end{tabular}

Data are expressed as mean \pm standard deviation

\begin{tabular}{|c|c|}
\hline No. of Patients & $(\mathrm{N}=60)$ \\
\hline Referred Shoulder Pain & $24(40)$ \\
\hline Abdominal Discomfort & $10(16.67)$ \\
\hline Hypotension & $16(26.7)$ \\
\hline Bradycardia & $16(26.7)$ \\
\hline Nausea/Vomiting & 0 \\
\hline Anxiety & 0 \\
\hline Respiratory Depression & 0 \\
\hline \multicolumn{2}{|c|}{$\begin{array}{c}\text { Table 2: Adverse Effects Observed } \\
\text { During the Surgery }\end{array}$} \\
\hline
\end{tabular}

Data are expressed as numbers of patients (\%).

Patients who complained of referred shoulder pain and abdominal discomfort were relieved after giving inj. pentazocine $15 \mathrm{mg}$ in 19 patients and in 5 cases repeat injection of another $15 \mathrm{mg}$ pentazocine was required to relieve the discomfort.

Hypotension occurred in sixteen patients who were treated primarily with intravenous fluids. In patients whose blood pressure were not responsive to fluid administration, inj. mephentermine was used. 7 of the patients responded to $6 \mathrm{mg}$ mephentermine and 4 patients had to be given 2 doses of $6 \mathrm{mg}$ mephentermine (i.e. $12 \mathrm{mg}$ ). Bradycardia occurred in sixteen patients all of whom were corrected by $0.6 \mathrm{mg}$ of atropine. None of the patients complained of nausea. There was no incidence of vomiting or respiratory depression in any of the patients.

None of the patients required conversion to general anaesthesia or conversion to open surgery. The Ramsay sedation score of the patients at 5 mins, 15 mins, and 25 mins from the start of the procedure and at the end of surgery are summarised in Fig. 3.

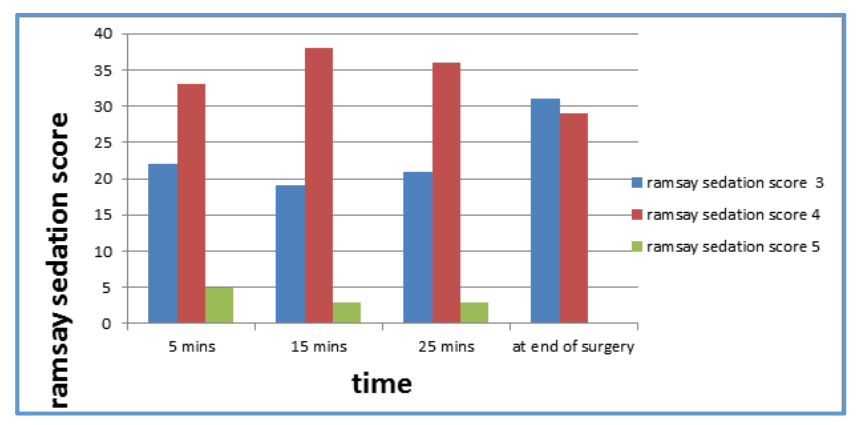

Fig. 3

The postoperative pain score was $1.8 \pm 1.5,2.8 \pm 2.2$, $2.2 \pm 1.3,1.2 \pm 1.0,0.8 \pm 0.9$ at 1 hr., 3 hrs., 6 hrs., 12 hrs., and 24 hrs. postoperative and it was satisfactory and is summarised in table 3. The degree of patient satisfaction was excellent, good, average, and poor in 8, 19, 29, and 4 patients, respectively.

\begin{tabular}{|c|c|}
\hline Time (Postoperative) & $\begin{array}{c}\text { Mean Postoperative Pain Score } \\
\text { (VAS) }\end{array}$ \\
\hline $1 \mathrm{hr}$. & $1.8 \pm 1.5$ \\
\hline $3 \mathrm{hrs}$. & $2.8 \pm 2.2$ \\
\hline $6 \mathrm{hrs}$. & $2.2 \pm 1.3$ \\
\hline $12 \mathrm{hrs}$. & $1.2 \pm 1.0$ \\
\hline $24 \mathrm{hrs}$. & $0.8 \pm 0.9$ \\
\hline \multicolumn{2}{|c}{} \\
\hline
\end{tabular}

\section{DISCUSSION}

In this study, gynaecological laparoscopic procedures of short duration were done under spinal anaesthesia along with continuous intravenous dexmedetomidine infusion. There was referred shoulder pain and abdominal discomfort in 24 and 10 patients, respectively, but were managed with injection pentazocine. Bradycardia and hypotension were observed in 16 patients each. None of the cases were converted to general anaesthesia or open surgery.

Shoulder tip pain, abdominal discomfort, and anxiety during intra-abdominal carbon dioxide pneumoperitoneum for laparoscopic procedures and their proper management is a major concern during the use of spinal anaesthesia in these cases. Amongst all the discomforts, carbon dioxide pneumoperitoneum-induced shoulder pain during laparoscopic surgery under spinal anaesthesia is the most distressing. Postoperative shoulder tip pain after general anaesthesia is easily managed by removing intra-abdominal residual carbon dioxide by applying active aspiration via the trocars ${ }^{[8]}$ or by lung recruitment manoeuvre.[9] However, intraoperative shoulder tip pain during regional anaesthesia is a leading cause of conversion to general anaesthesia.[10,11]

Carbon dioxide gas insufflations in the abdomen and the head-down tilt position causes abdominal discomfort and referred shoulder tip pain.[12] In order to minimise these discomforts, dexmedetomidine infusion was used. The analgesic and sedative effects of dexmedetomidine were expected to resolve the pain and discomfort during the carbon dioxide pneumoperitoneum without causing respiratory depression. Intravenous dexmedetomidine infusion was given till the intra-abdominal carbon dioxide gas was deflated. In this study, intravenous pentazocine $(15 \mathrm{mg})$ is used as a supplement for its sedative as well as analgesic effect.

Dexmedetomidine as well as spinal anaesthesia are both commonly associated with adverse effects like hypotension and bradycardia. In a phase-III study of 401 patients, the incidence of hypotension and bradycardia associated with dexmedetomidine were $30 \%$ and $9 \%$, respectively.[13] The incidence of hypotension increases with an increase in the dose of dexmedetomidine ${ }^{[14]}$ whereas the incidence of bradycardia is not related to the increase in the dose of dexmedetomidine. Some studies have also shown that dexmedetomidine use during spinal anaesthesia is associated more frequently with bradycardia than hypotension.[7] At intra-abdominal pressures of $<15 \mathrm{mmHg}$, venous return, cardiac filling pressure, and cardiac output are increased as blood is squeezed from the splanchnic circulation as well as by peripheral vasoconstriction.[15] The insertion of the Veress needle or trocar and the peritoneal stretching caused by pneumoperitoneum can cause vagal stimulation thereby causing bradycardia. ${ }^{[16]}$ 
In this study, none of the patients complained of nausea and there was no incidence of vomiting in any of the patients, which correlates with the study of Sinclair et al[17] who found that there was an 11-fold decreased risk for nausea and vomiting in patients receiving regional anaesthesia as compared with those receiving general anaesthesia.

Further studies have to be done by including larger number of patients and with a comparison group or a placebo. Moreover, the effects of various maintenance doses of dexmedetomidine $(0.2-0.7 \mu \mathrm{g} / \mathrm{kg} / \mathrm{hr}$.) need to be evaluated to calculate the optimum maintenance dose.

In conclusion, this study has shown that spinal anaesthesia with dexmedetomidine infusion maybe used for short gynaecological laparoscopic procedure thereby avoiding intubation and its associated complications. There is however always a need of supplemental analgesia, sedation, and careful monitoring during the procedure.

\section{REFERENCES}

1. Pursnani KG, Bazza Y, Calleja M, et al. Laparoscopic cholecystectomy under epidural anaesthesia in patients with chronic respiratory disease. Surg Endosc 1998;12(8):1082-4.

2. Gramatica L, Brasesco OE, Luna MA, et al. Laparoscopic cholecystectomy performed under regional anaesthesia in patients with obstructive pulmonary disease. Surg Endosc 2002;16(3):472-5.

3. Tzovaras G, Fafoulakis F, Pratsas K, et al. Laparoscopic cholecystectomy under spinal anaesthesia: a pilot study. Surg Endosc 2006;20(4):580-2.

4. Sinha R, Gurwara AK, Gupta SC. Laparoscopic cholecystectomy under spinal anaesthesia: a study of 3492 patients. J Laparoendosc Adv Surg Tech A 2009;19(3):323-7.

5. Gautam B. Spinal anaesthesia for laparoscopic cholecystectomy: a feasibility and safety study. Kathmandu Univ Med J 2009;7(28):360-8.

6. Grewal A. Dexmedetomidine: new avenues. J Anaesthesiol Clin Pharmacol 2011;27(3):297-302.
7. Niu XY, Ding XB, Guo T, et al. Effects of intravenous and intrathecal dexmedetomidine in spinal anaesthesia: a meta-analysis. CNS Neurosci Ther 2013;19(11):897-904.

8. Das K, Karateke F, Menekse E, et al. Minimising shoulder pain following laparoscopic cholecystectomy: a prospective, randomised, controlled trial. J Laparoendosc Adv Surg Tech A 2013;23(3):179-82.

9. Phelps P, Cakmakkaya OS, Apfel CC, et al. A simple clinical manoeuvre to reduce laparoscopy-induced shoulder pain: a randomised controlled trial. Obstet Gynaecol 2008;111(5):1155-60.

10. Hamad MA, El-Khattary OA. Laparoscopic cholecystectomy under spinal anaesthesia with nitrous oxide pneumoperitoneum: a feasibility study. Surg Endosc 2003;17(9):1426-8.

11. Lee JH, Huh J, Kim DK, et al. Laparoscopic cholecystectomy under epidural anaesthesia: a clinical feasibility study. Korean J Anaesthesiol 2010;59(6):3838.

12. van Zundert AA, Stultiens G, Jakimowicz JJ, et al. Laparoscopic cholecystectomy under segmental thoracic spinal anaesthesia: a feasibility study. Br J Anaesth 2007;98(5):682-6.

13. Bhana N, Goa KL, McClellan KJ. Dexmedetomidine. Drugs 2000;59(2):263-8.

14. Song J, Kim WM, Lee SH, et al. Dexmedetomidine for sedation of patients undergoing elective surgery under regional anaesthesia. Korean J Anaesthesiol 2013;65(3):203-8.

15. Odeberg $\mathrm{S}$, Ljungqvist $\mathrm{O}$, Sevenberg $\mathrm{T}$, et al. Haemodynamic effects of pneumoperitoneum and the influence of posture during anaesthesia for laparoscopic surgery. Acta Anaesthesiol Scand 1994;38(3):276-83.

16. Sprung J, Abdelmalak B, Schoenwald PK. Recurrent complete heart block in a healthy patient during laparoscopic electrocauterisation of the fallopian tube. Anaesthesiology 1998;88(5):1401-3.

17. Sinclair DR, Chung F, Mezei G. Can postoperative nausea and vomiting be predicted? Anaesthesiology 1999;91(1):109-18. 